\title{
EFFECT OF MAGNETIC FLUX FRINGING AT POLE EDGES ON PARAMETERS AND PERFORMANCE OF E-CORE HETEROPOLAR LINEAR SYNCHRONOUS MOTOR
}

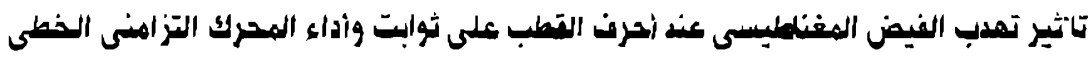

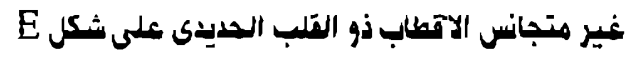 \\ Dr. S. A. El-Drieny \\ Electrical Engineering Department, \\ Faculty of Engineering, El-Mansoura University, \\ El-Mansoura, Egypt
}

ملذص البحث

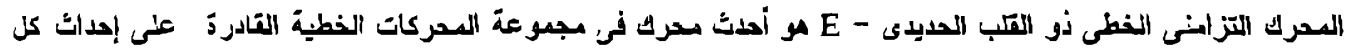

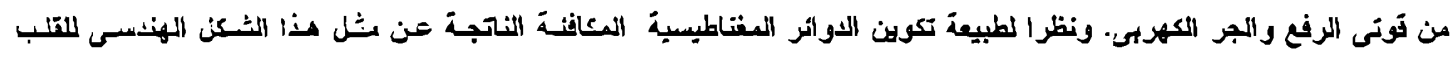

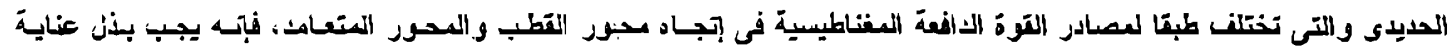
خاصة عند حساب ثنوايت الآله

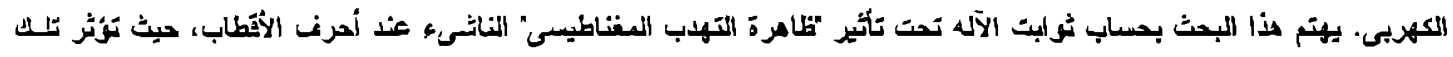

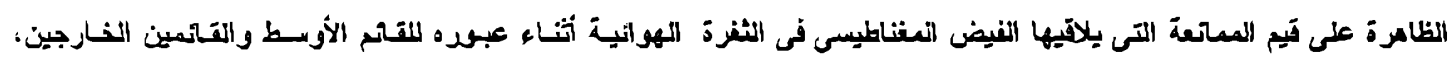

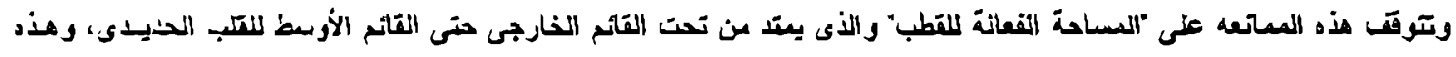

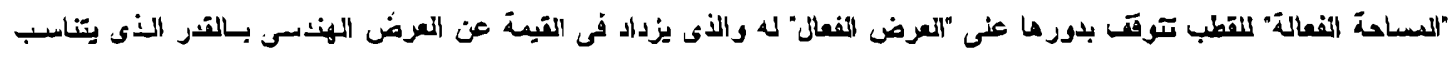

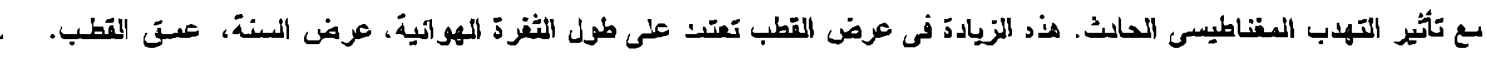

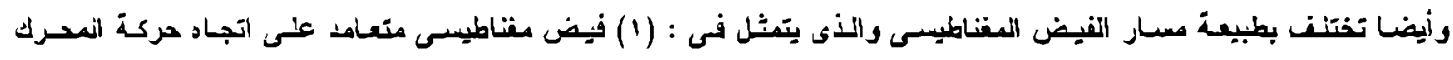

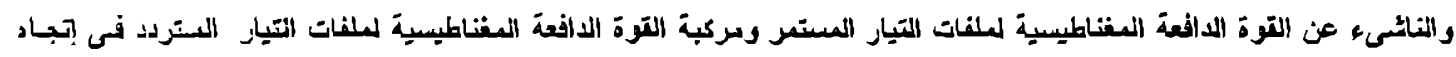

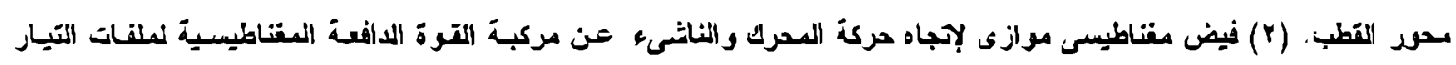

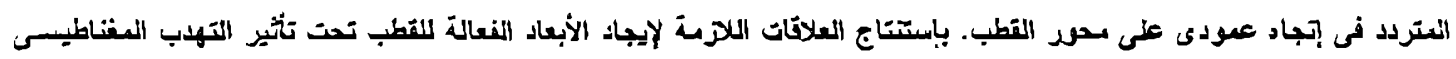

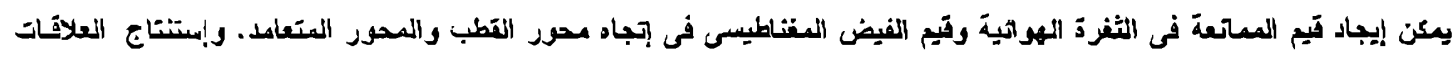

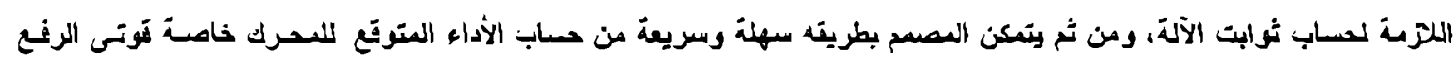

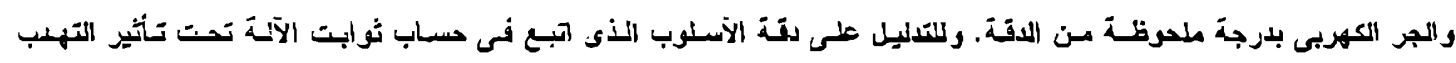

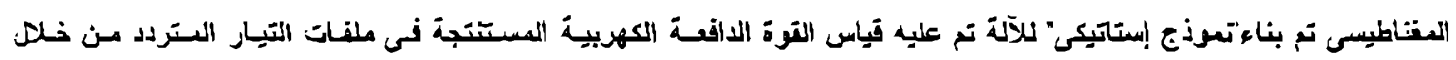

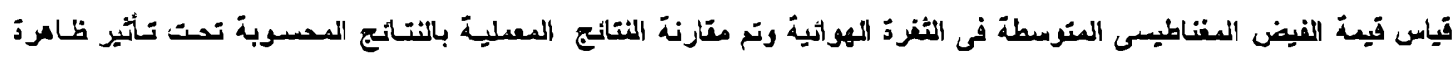

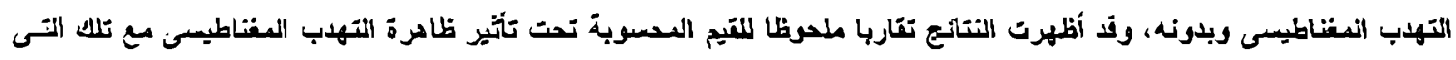

\section{ABSTRACT}

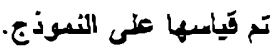

Recently, the E-core linear synchronous motor has becn introduced to the family of lincar motors capablc of cxerting both traction and attraction forces. Due to the complexity of the magnetic structure of such core-shape, attention must be paid while evaluating the machine parameters. Thereby. more exact estimation of the expccted machine performance can be cnsured.

This paper is coneerned mainly with the proper evaluation of the parameters of the E-core linear synchronous motor: taking into consideration the flux fringing effect. This effect is one of the most important factors which influcnce the air-gap reluctanee faced by both the transverse and tangitudinal fluxes. The developed approach to simulate the flux fringing in the air-gap regions has been resulted in a simple way to get the effective pole arcas under the middle and outer limbs. Accordingly, the values of center air-gap permeance 
corresponding to different alr-gap flux components $C_{\phi}, \phi_{a d}, \phi_{a q}{ }^{2}$ and intern the machine parameters $C_{a f}, L_{f}, L_{a d}$, $L_{a q}{ }^{2}$ can be exactly evaluated. This way, the machine performance. especially the traction and attraction forces, can be properly and easily predicted at this phase of motor design process.

Experimental measurements are carried out on a simple static model to verify the proposed approach. The comparison between the theoretical results. considering effect of magnetic flux fringing at pole edges, and experimental results on a static prototype motor shows that they are in a good agreement.

\section{INTRODUCTION :}

Linear motors with transverse magnet1c circuit providing both traction and aturaction forces were introduced in 1972 [1] A recent addition to this class of $I$ inear motors is the $E$-core type [2] and it is show in Fig. (1). Several complicated magnetic circuits are established in this machine due to its core shape and the type of MMF along a given magnetic axis. Therefore attention must be paid during the estimation process of the parameters of this motor. If these parameters are not exactly estimated. the traction force required will not match with the required attraction force. This paper is concerned with the parameters evaluation of the $\Xi$-core linear synchronous motor; taking into account the phenomena of flux fringing at pole odges. This phenomena affects the air-gap permeance under the middle and outer core limbs. Accordingly, the air-gap permeances are influenced by both the type of excitation CDC and $A C$ excitation and the effective pole area. The total flux along the d-axis, due to the DC excitation and the corresponding component of the AC excitation. crosses the central air-gap in a direction normal to the motion. Similariy, the flux along the q-axis. due to the corresponding component of the AC excitation. crasses the central air-gap in a direction tangential to the motion. Regarding the pole area, there are two effective pole areas, one under the middle core $1 \mathrm{imb}$ and the other under the outer core $1 \mathrm{imb}$. The eifective pole area is greater than the geometric pole area by an amount sufficient to compensate the fringing magnetic flux at pole edges. For a given dimension of E-core especially the widths of middle and outer $1 \mathrm{imbs}$, the effective pole area depends on the pole width. The increased amount of pole width depends on : air-gap. tooth width and pole depth. Once the effective pole areas under the middle and outer core limbs have been estimated, considering the effect of magnetic flux fringing at pole edges, the air-gap permeances, the flux components. the inductances, the attraction and traction forces were estimated.

The given approach depends on the assumption of neglecting end-loss. saturation in all iron parts, all $f l u x$ leakage and all harmonies in Mar produced by $A C$ and $D C$ windlings. To verify the given approach an experimental tests were carried out on a prototype static motor. This. prototype was built in electric machine laboratory, El mansoura University. The induced e.m. $f$ was measured in $A . C$ windings using the average value of the flux at pole pitch. The comparison between experimental results and theoretical one inclusive effect of magnetic flux fringing at pole edges show that they are more close together.

\section{Air-gap Permeance :}

To get the centre alr-gap permeance $S$ assuming the corresponding flux paths to follow clrcular fringes outside the gap as indicated in Fig. ( $2 a$ \& $2 b$ ), and the air-gap, g. is multiplied by Carter's 
coefficient to allow for slotting of the stator. In accordance with $S_{2}$, the outside air-gap permeance, the division of flux paths is similar to that of $S_{1}$.

The flux carrying region can be divided into seven individual reglons possessing the following permeances [ 6 ].

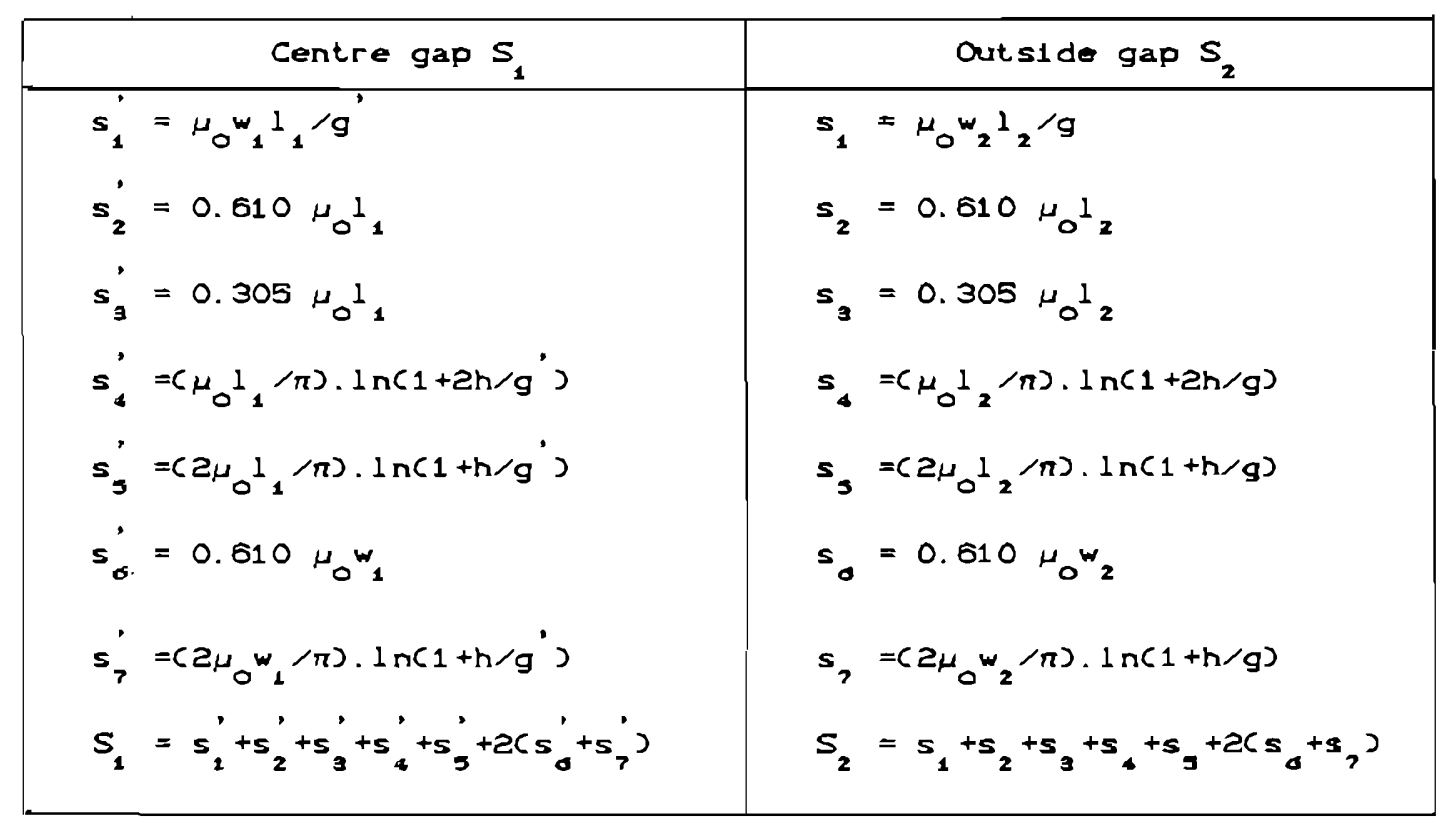

$$
s_{1}=\mu_{0} \cdot A_{10 \text { or }} / g^{\prime}=s_{1}^{\prime}+s_{2}^{\prime}+s_{3}^{\prime}+s_{1}^{\prime}+s_{5}^{\prime}+2\left(s_{0}^{\prime}+s_{1}^{\prime}\right)
$$

$A_{1 \text { of } l}=\frac{4 w_{1} g^{\prime}}{n} \ln \left(1+h / g^{\prime}\right)+\frac{1_{1} g^{\prime}}{n} \ln \left(1+2 h / g^{\prime}\right)+\frac{2 l_{1} g^{\prime}}{n} \ln \left(1+h / g^{\prime}\right)+$

$$
+1.32 g w_{1}+w_{1} 1_{2}+0.915 g{ }^{\prime}{ }_{1}
$$

Consequently the increased amount area under centre air-gap is given by: $\Delta a_{1}=A_{1 \in f}-w_{1} l_{1}=\frac{4 w_{1} g^{\prime}}{\pi} \ln \left(1+h / g^{\prime}\right)+\frac{1_{1} g^{\prime}}{\pi} \ln \left(1+2 h / g{ }^{\prime}\right)+\frac{2 l_{1} g^{\prime}}{\pi} \ln \left(1+h / g^{\prime}\right)+$

$$
+1.32 g w_{1}+0.915 g \dot{1}_{1}
$$

In similar the increased amount area under outer air-gap 15 given by:

$\Delta a_{2}=\frac{4 w_{2} g}{\pi} \ln (1+h / g)+\frac{1_{2} g}{\pi} \ln (1+2 h / g)+\frac{2 l_{2} g}{\pi} \ln (1+h / g)+$

$$
+1.32 g w_{2}+0.915 \mathrm{~g} \mathrm{I}_{2}
$$




\section{Prediction of Performance Characteristics :}

3.1. Field Winding Mutual and $\operatorname{Sel} f$ Inductances $\left(M_{\text {af }}\right.$ and $\left.L_{f}\right)$ :

The field flux takes a transverse paths fig. (1), crossing a two air-gaps in each pole pitch and giving a flux density under the centre -imb as following:

$\geq Z_{1} I_{1}=H_{1} g+H_{2} g$

$2 Z_{i} I_{r}=\left(g / \mu_{0}\right)\left(B_{1 f}+B_{2}\right)$

$D=B_{11} A_{1}=B_{2} A_{2}$ assuming zero pole leakage.

$=B_{1 f} w_{1} 1_{1 d}=B_{2} w_{2} 1_{2}$

$3_{2}=B_{1 f}\left(w_{1} 1_{1 d}-w_{2} 1_{2}\right)$

from (1) and (2)

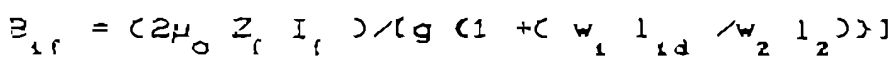

The total flux per pole is equal to the average fiux density over the whole pole width multiplied by the air-gap area $\left(\tau_{p} \cdot \omega_{1}\right)$, where :

$\phi_{p}=\left(w_{1} \cdot \tau_{p}\right) \cdot\left(\left(4 B_{1 f} / \pi^{2}\right) \cdot \sin \left(\frac{\pi}{2} \cdot \frac{\left.\left.1, \frac{1 d}{\tau_{p}}\right)\right)}{p}\right.\right.$

and,

$\left.p_{i}=\left(w_{1} \cdot \tau_{p}\right) \cdot\left(s / \pi^{2}\right) \cdot\left[\left(\mu_{0} \cdot Z_{f} \cdot I_{i}\right) / 4 g\left(1+\left(w_{1} 1_{1} d\right) /\left(w_{2} l_{2}\right)\right)\right\}\right] \cdot \sin \left(\frac{\pi}{2} \cdot \frac{l_{1} d}{\tau_{p}}\right)$

The induced RMS phase voltage can be expressed in terms of a mutual inductarce or a rate of change of flux, i.e.,

$M_{a f} \cdot I_{f}=2(1 / \sqrt{2}) \cdot\left(z_{a} \cdot G \cdot K_{w} \cdot p\right) \cdot \phi_{f}$

Substituting for $\phi$ from equation (a) into equation (10) gives the nutual inductance linklng the rield and armature windings.

$M_{o f}=\frac{8 \sqrt{2} \cdot w_{1} \cdot \tau_{p} \cdot \mu_{0} \cdot z_{f} \cdot p\left(z_{a} \cdot q \cdot k_{w}\right)}{\pi^{2} \cdot g \cdot\left(1+\left(w_{1} \cdot 1_{1 d}\right) /\left(w_{2} \cdot 1_{2}\right)\right)} \cdot \sin \left(\frac{\pi}{2} \cdot \frac{1_{1 d}}{\tau_{p}}\right)$

The instantaneous voltage induced in the rield winding can be expressed in terms of a self inductance or a rate of change of flux. Since the field winding consists of two series connected sections, the voltage is given by:

$L_{r} \cdot \frac{d I_{r}}{d t}=2 \cdot Z_{r} \cdot P \cdot \frac{d \phi_{r}}{d t}$

Using equations ( 7$)$, ( 8$)$ gives the field winding self inductance 


$$
\begin{aligned}
& -L_{f} \cdot \frac{B_{1 f} \cdot g \cdot\left(1+\left(w_{1}^{\prime} 1_{1 d} / w_{2} l_{2}\right)\right.}{\mu_{0} \cdot Z_{t}}=2 Z_{1} \cdot p \cdot \frac{8 B_{1 f}}{\pi^{2}} \cdot w_{1} \cdot \tau_{p} \cdot \sin \left(\frac{\pi}{2} \cdot \frac{1_{i d}}{\tau_{p}}\right) \\
& \text { then, } \\
& L_{i}=\frac{16 \mu_{0} \cdot Z_{i}^{2} \cdot p \cdot w_{1} \cdot T_{p}}{\pi^{2} \cdot g \cdot\left(1+\left(w_{1} 1_{1 d} / w_{2} 1_{2}\right)\right)} \cdot \sin \left(\frac{\pi}{2} \cdot \frac{1_{1 d}}{T_{p}}\right) \\
& \text { 3.2. Armature q-axis Self Inductance } L_{a q}: \\
& \text { The q-axis fleld takes longitudinal paths [3], see Fig. (1), through } \\
& F_{a q}(x)=\hat{F}_{a} \sin \left(\pi x<\tau_{p}\right) \quad 0 \leq x \leq \tau_{p} \\
& \phi_{q_{2}}=2 \frac{\mu_{a} w_{1}}{q} \hat{F}_{a} \int_{1 q^{\prime 2}}^{\tau_{p}^{\prime 2}} \frac{\sin \pi^{x / \tau_{p}}}{(\pi / 2) \cdot\left(2 x-1_{1 q} / 2\right)} \cdot d x \\
& \phi_{q}=c_{q} \cdot \frac{6 \cdot\left(Z_{a} \cdot q \cdot x_{w}\right) \cdot \mu_{0} \cdot w_{1} \cdot T_{p} \cdot I}{\sqrt{2} \cdot \pi^{2} \cdot g} \\
& c_{q}=\frac{1}{\pi_{p} q}-\frac{1}{\pi} \cdot \sin \left(\frac{\pi}{2} \cdot \frac{1}{T_{p}}\right)
\end{aligned}
$$


$L_{a q}=c_{q} \cdot \frac{\sigma \cdot\left(z_{a} \cdot r_{1} \cdot k_{w}\right)^{2} \cdot \mu_{0} \cdot w_{1} \cdot \tau_{p} \cdot p}{\pi^{2} \cdot g}$

3. 3. Armature a-axis Self-1nductance $\left(L_{\text {ad }}\right)$ :

The rlux created by the armature winding is divided into two $r l u x$ components in both $d$ and $q$ axes. The $d$-axis armature steld takes transverse paths [4], as the main rield created by the D.C. excitation - see Fig.(1). So, the same technique used to predict the behaviour of the maln fleld can be used to predict the d-axis armature rield. This an be analyzed using a magnetic equivalent circuit similar to that of the D.C. excltation with slight difference. Mis difference is due to the existence of the A.C. excitation on the centre $1 \mathrm{imb}$ of the core.

As the A.C. winding is a distributed one, the corresponding source of m.m.f. Is distributed sinusiodally along the direction of the machine length. The equivalent $m$.m. $r$. In the direct axis, $F_{\text {od }}$, is calculated by summing the flux contributions from each element under the centre air-gap as rollowings :

The direct axis component of armature m.m. $r$. at any point $x$ from the centre pole along the machine length, assumlng unity power ractor is given as $[5]$;

$F_{\text {ad }}=\hat{F}_{a} \cdot \cos C_{\tau_{p}}^{\pi x} \quad 0 \leq x \leq \tau_{p}$

whereas the flux enters the pole equal to the rlux exits from it, therefore the total rlux in the centre air gap within the pole width must be zero hence;

$d \phi=0=\left(\mu_{0} \cdot \frac{w_{1}}{g}\right) \int_{-I_{1 d} / \tau}^{+1}\left(\hat{F}_{a} \cdot \cos \left(\frac{\pi x}{\tau_{p}}-F_{o d}\right) \cdot d x\right.$

then,

$F_{\text {od }}=\hat{F}_{a} \cdot \frac{\tau_{p}}{\pi \cdot 1_{1 d} / 2} \cdot \sin \left(\frac{\pi}{2} \cdot \frac{1 d}{\tau_{p}}\right)$

(21)

The flux under the outer-gap is uniform distributed, this confirmed that under unsaturated condition the pole surface may considered as an. equipotential surface. Assuming that there is no leakage between the " adjacent poles, so the pole potential can be found easily by equating the flux crossing the centre gap to that crossing the outer-gap.

$\phi_{\text {cantre-gap }}=\phi_{\text {ouler-gap }}$

$\left(F_{\text {od }} \sim F_{p}\right) \cdot S_{1}=F_{p} \cdot S_{2}$

$\left[\hat{F}_{a} \cdot \frac{2}{\pi} \cdot \frac{\tau p}{l_{1 d}} \cdot \sin \left(\frac{\pi}{2} \cdot \frac{1, d}{\tau_{p}}\right)-F_{p}\right] \cdot S_{1}=F_{p} \cdot S_{2}$ 
When the above equation is solved for $F_{p}$, the rundamental component of the centre limb air-gap flux density and then the polie flux cian be obtalned :

$\phi_{d}=c_{d} \cdot \frac{\sigma \cdot\left(z_{a} \cdot q \cdot K_{w}\right) \cdot \mu_{0} \cdot w_{i} \cdot \tau_{p} \cdot I}{\sqrt{2 \cdot r^{2} \cdot g}}$

Where:

$c_{d}=\frac{1_{1 d}}{\tau_{p}}-\frac{1}{\pi} \sin \left(\frac{\pi}{2} \cdot \frac{1_{1 d}}{\tau_{p}}\right)-\frac{8 \tau_{p}}{\pi^{2} \cdot 1_{1 d}\left(1+\left(1_{2} w_{2} / 1_{1 d} w_{i}\right)\right.} \cdot \sin ^{2}\left(\frac{\pi}{2} \cdot \frac{1_{1 d}}{\tau_{p}}\right)$

Equating the expressions for the induced emf $\varepsilon_{\text {ad }}$ and the air-gap direct reactance voltage drop $I_{d} . X_{d}$, the armature d-axis inductance can be obtained:

$L_{a d} \cdot I=\frac{2 \cdot\left(Z_{a} \cdot q \cdot k_{w}\right)}{\sqrt{2}} \cdot P \cdot \phi_{d}$

$L_{a d}=c_{d} \cdot \frac{\left.6 \cdot C z_{a} \cdot q \cdot K_{w}\right)^{2} \cdot \mu_{0} \cdot w_{1} \cdot \tau_{p} \cdot p}{\pi^{2} \cdot g}$

\section{4. Thrust and Attractive Force:}

By means of conventional two-axis theory the voltage matrix equation can be represented by:

$$
v=r \cdot 1+L \cdot G d t / d t\rangle+\omega \cdot G_{i}
$$

In this expression :

$i=$

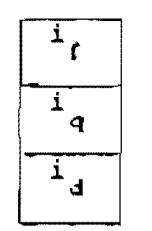

$L=$

\begin{tabular}{|l|l|l|}
\hline$L^{f}$ & & $M$ \\
\hline$M^{f}$ & & $L^{d}$ \\
\hline
\end{tabular}

$\mathbf{G}=$

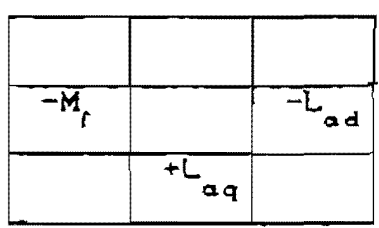

$L_{d}, L_{q}$ and $L_{f}$ include leakage components, 1.e. .

$L_{d}=L_{i d}+L_{a d}$ etc. Equation (26) can be written as:

$i^{T} \cdot v=i^{T} \cdot R \cdot i+\frac{d}{d t} \cdot\left(1^{T} \cdot L \cdot i\right)+\omega \cdot 1^{T} \cdot G \cdot 1$

Where, $i^{T}$ indicates the transpose or 1 , so that each term of the machine power balance can be identified. Equating the converted power to the mechanical power output gives: 
echanical power output $=\omega \cdot\left[M_{1} \cdot I_{1} \cdot i_{q}+C L_{a d}-L_{a q}{ } \cdot i_{d} \cdot I_{q}\right]$.

$n$ terms of steady-state quantities:

$$
\begin{aligned}
& i_{f}=I_{f}, i_{d}=\sqrt{3} \cdot I \cdot \cos \delta_{i}, i_{q}=\sqrt{3} \cdot I \cdot \sin \delta_{i}, \\
& M_{a f}=M_{f} / \sqrt{3}, \text { periphery speed }=\tau_{p} \cdot \omega, \pi \text {, so that: } \\
& \text { The Torque }=3 \cdot M_{a f} \cdot I \cdot I_{f} \cdot \sin \delta_{i}+\frac{3}{2} \cdot\left(L_{a d}-L_{a q}\right) \cdot I^{2} \cdot \sin 2 \delta_{i}
\end{aligned}
$$

The thrust force under constant current conditions may given by ;

$$
\left.F_{T}=\frac{3 \pi}{\tau_{p}} \cdot M_{a f} \cdot I_{t} \cdot I \cdot \sin \delta+\frac{3 \pi}{2 \tau_{p}} \cdot C L_{a d}-L_{a q}\right) \cdot I^{2} \cdot \sin 2 \delta_{i}
$$

The calculated thrust force is shown in Ejg. (3). A consideration of the air-gap stored energy leads to the following attraction force $F_{N}$ where :

$N=\frac{\partial}{\partial g}$ (stored energy) $=\frac{\partial}{\partial g}\left(i^{T} \cdot L, i\right)$

$$
=\frac{\partial}{\partial g}\left[\frac{1}{2} L_{f} \cdot i_{t}^{2}+\frac{1}{2} L_{q} \cdot i_{q}^{2}+\frac{1}{2} L_{d} \cdot i_{d}^{2}+M_{f} \cdot i_{d} \cdot i_{f}\right]
$$

ivaluating this expression gives ;

$$
i_{N}=\frac{L_{f} \cdot I_{r}^{2}}{2 g}+\frac{3 I^{2}\left(L_{a d}+L_{a q}{ }^{2}\right.}{4 g}+\frac{3 I^{2}\left(L_{a d}-L_{a q}{ }^{2}\right.}{4 g} \cos 2 \delta_{i}+\frac{3 M_{a r} \cdot I_{r} \cdot I}{9} \cos \delta_{i}
$$

Since the leakage inductance are independent of $g$. Equation (29) shows that there are two normal rorce components that are 1 ndependent if torque angle $\left(\delta_{i}\right)$ and two variable force components. The calculated iormal force is shown in Fig. (4). The larger of these varies as ccos is and is due to the interaction between the armature and rield urrent distributions.

\section{PROTOTYPE MOTOR AND EXPERTMENTAL RESULTS :}

The prototype motor is made of mild steel sections with a laminated and wound centre core. The D.C. coil is positioned under the armature dinding in the centre core 1 imo. The armature windings are 3-phase with 2-slot/pole/phase and double layer winding. The poles are made of solid nild steel and have T-shape. The D.C. coils are excited from the D.C. supply and the induced e.m. $f$. per phase is measured in AC windings using" che measured average value of the flux at pole pitch, se Fig. (5). It san be seen rrom Fig.(5) that. the experimental measurements or E.M.F. is quite close to theoretical E.M.F. When the erfect or magnetic riux. fringing at the pole edges is considered. The prototype motor has the rollowing data :- 


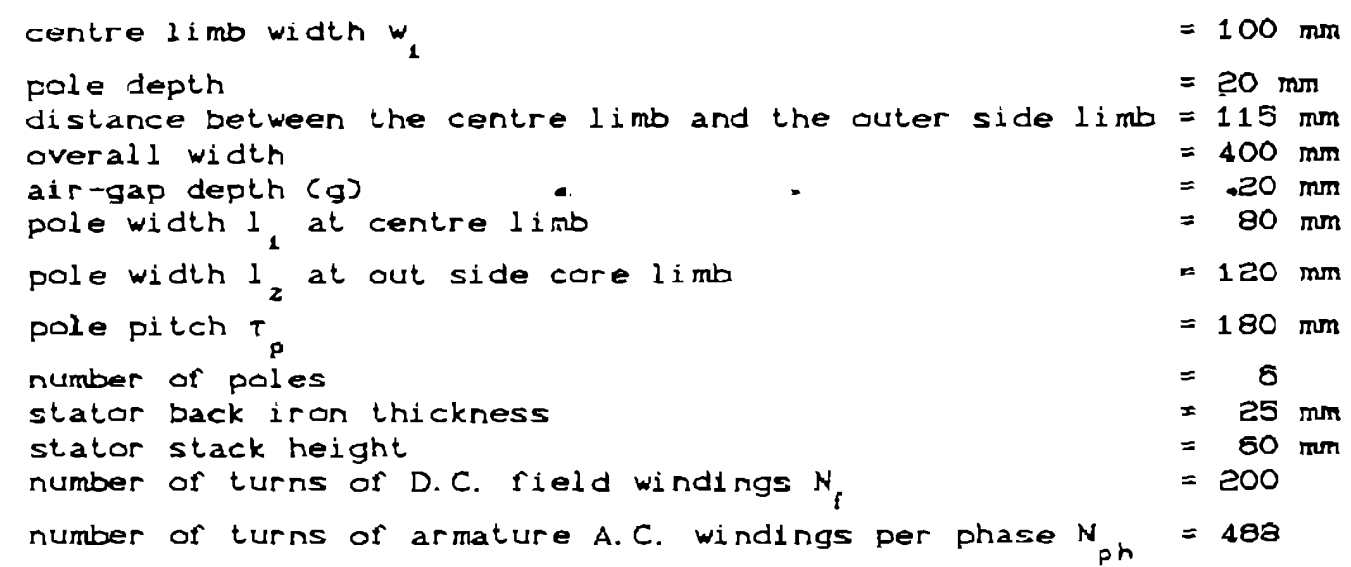

\section{CONCLUSION :}

In this paper, relations determining the air-gap reluctance of E- core linear synchronous motor have been taking into consideration the efrect of the magnetic field fringing in the air-gap regions. In these relations, the concept of "effective pole-area" and "effective pole width" are introduced to enable mere precise and quick calculations of the machine parameters.

As the arialysis reveals, the erfect of magnetic field fringing results in increasing the geometrical pole-area by a fictitious amount ; reducing thereby the air-gap reluctance. The corresponding reduction has naturally its effect on the machine parameters and, inturn, on the machine performance.

The laboratory measurments, carried out on the prototype motor, show that the induced E.M.F. in the armature windings due to the main excitation has a good correlation with that theoretically investigated taking into consideration the magneti flux fringing at pole edges.

The presented analysis and suggested concepts give a precise. short cut tool in the machine designer hand.

\section{LIST OF SYMBOLS :}

$A_{\text {lof }}:=$ Effective pole area under the centre limb.

$A_{20 f t}:=$ Erfective fole area under the outer $1 \mathrm{imb}$.

$B_{1}:$ : = Centre air-gap flux density.

$\hat{F} \quad:=$ The peak value of resultant armature m.m.f. distribution.

F, : $\quad$ Field m.m. .

$F_{\text {p }} \quad:=$ Pole magnetic potential.

g. : = Alr-gap length at the pole centre.

- $\mathbf{g}:=$ effective air-gap length inclusive Carter's coefficient.

h $\quad:=$ pol depth.

I : : The rms armature current.

If $:=$ Field current.

$\mathrm{K}_{w} \quad:=$ Fundamental winding ractor.

$1 .:=$ Pale width under centre core $11 \mathrm{mb}$.

1.' : = Pole width under outside core limb. 
$1_{1 d}:=$ Effective pole wldth under centre core limb in d-axis position.

$1_{1 q}:=$ Effective pole width under centre core limb in q-axis position.

$12:=$ Efrective pole width under outslde core $1 \mathrm{imb}$.

$L_{f} \quad:=$ Field winding sel $r$ induction exclusive leakage component.

Lad : =Armature d-axis self inductance exclusive leakage component.

$L_{\text {oq }}:=$ Armature a-axis self inductance exclusive leakage component.

$p:$ : = Number of pole pairs.

a : : $=$ Slots/pol e/phase.

$s \quad:=$ Slot width.

$S_{1}:=$ Centre air-gap permeance.

$S_{2}:=$ outer air-gap permeance.

$w_{1}:=$ Centre core $1 \mathrm{imb}$ width.

$w_{2}:=$ Outside core limb width.

$z_{a}:=$ Number of armature conductors per slot.

$z_{f}:=$ Number of field conductors.

$\tau_{p}:=$ Pole pitch.

$\mu_{0}:=$ Permeability of free space.

$\delta_{i}:=$ Torque angle.

$\phi_{1}:=$ Centre air-gap $r l u x$.

$\phi_{2}:=$ outer air-gap $f l u x$.

\section{REFERENCES}

1. Levi, E. "High speed iron synchronous operating linear motor" I.E.E Conference publication on linear electric machines No 120. Oct. 1974.

2. Wi seman, R.W. "Graphical determination of magnetic fields "Trans A. I.E.E Vol 4, No. 2, PP $141-154$ feb. 1972.

3. Eastham, J.F " Iron cored 1 inear synchronous machines " Electronic and power IEE Vol 23, 1977 PP 239, 242.

4. Eastham, J. F. and Balchin, M. J. " Characteristic of heteropolar Iinear synchronous machines with passive secondary "IEE Vol 2 , No. 6 Dec. 1979 pP 213-218.

5. Liwschitz Garik and Whipple, C.C. "Electrlc Machinery " Vol. 2 . Van. Nostrand.

6. EL-Drieny. S. A. "Analysis of claw pole transverse flux inductor motor by means of magnetic equi,yalent circuit". Mansoura Engineering Journal. Vol. 12, No. 2, Dec. 1987. 

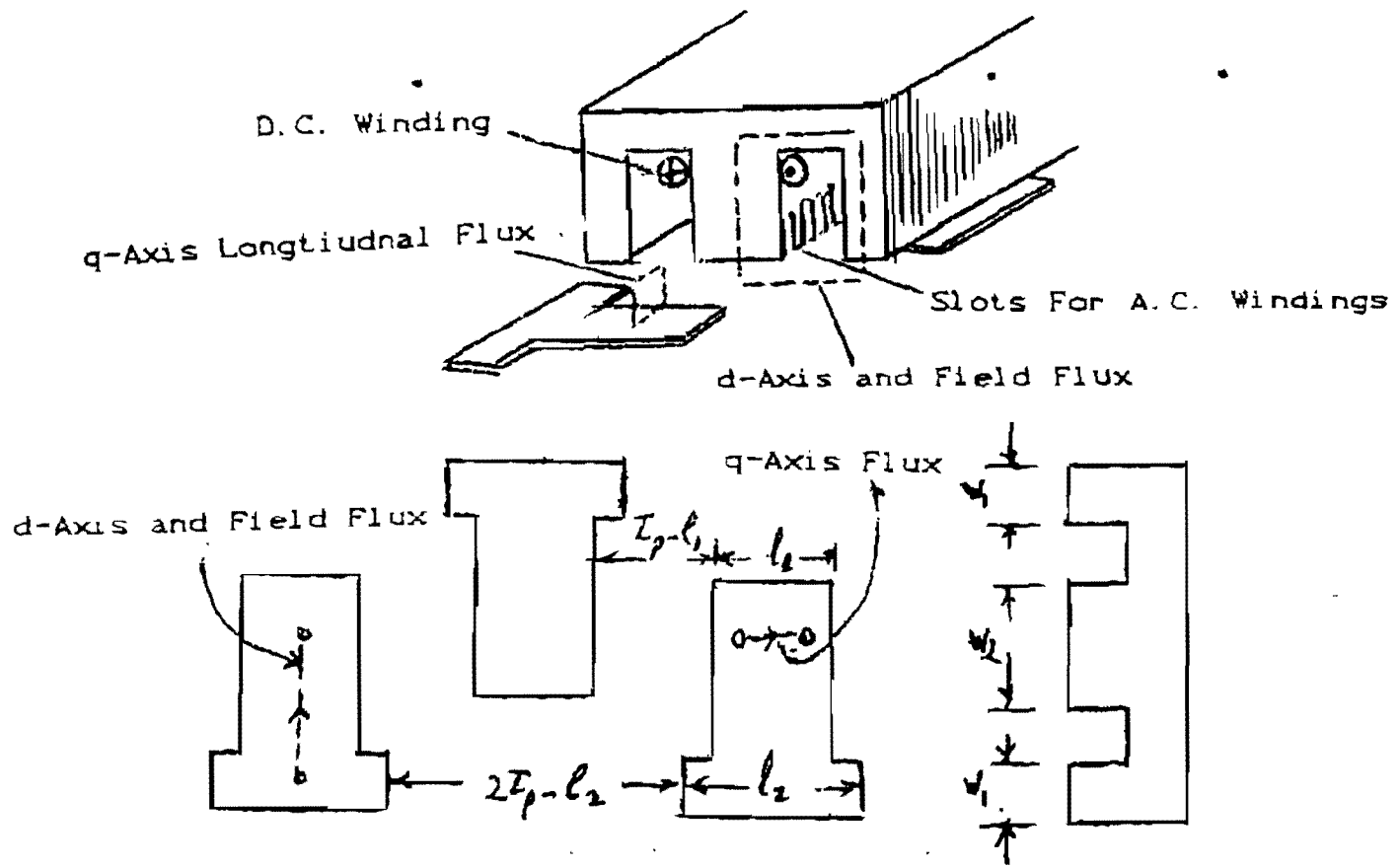

Fig. (1): E-core Transverse Flux Hetropolar Linear Synchronous Motor and Magnetis $C_{1}$ reuit Dimensions.

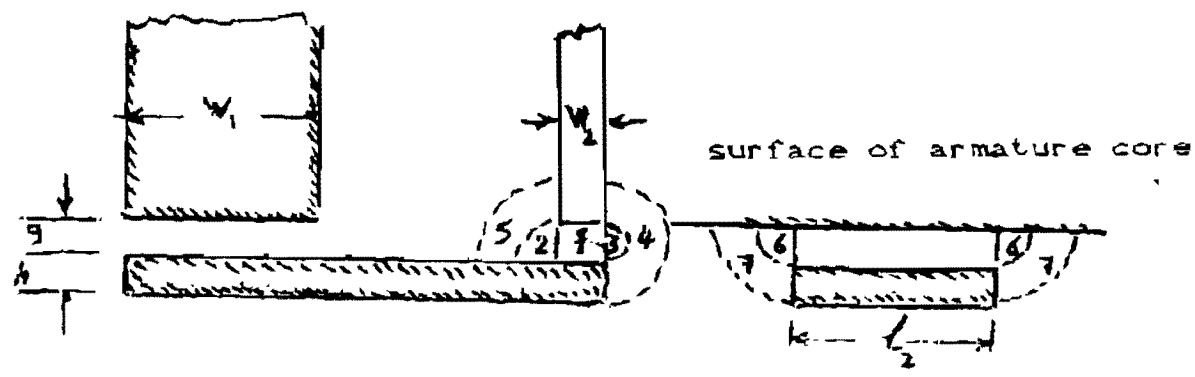

Fig.(Za) : Division of side air-gap into component flux paths.

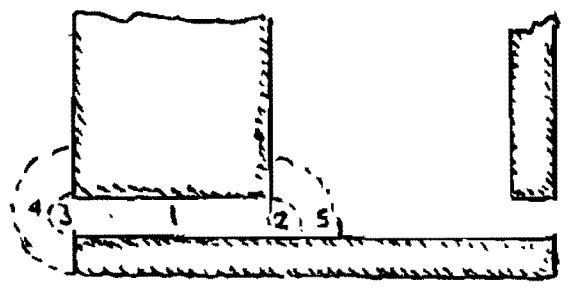

surface of armature core

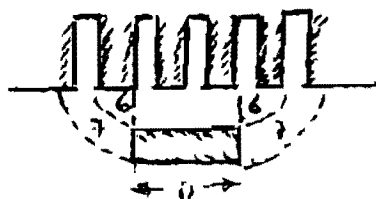

Fig.(2b): Duvision of centre air-gap into component flux paths. 


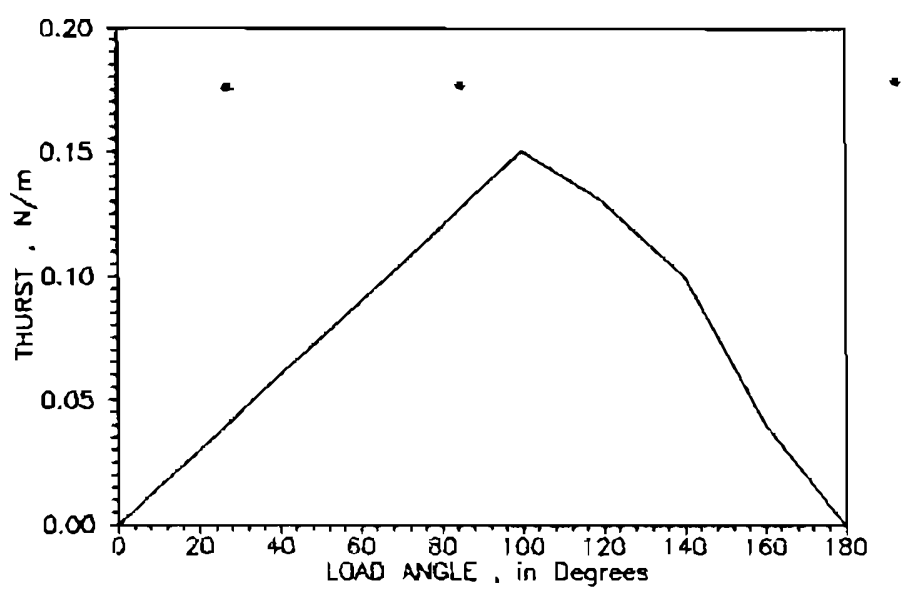

Fig.(3): Thrust force versus lood ongle.

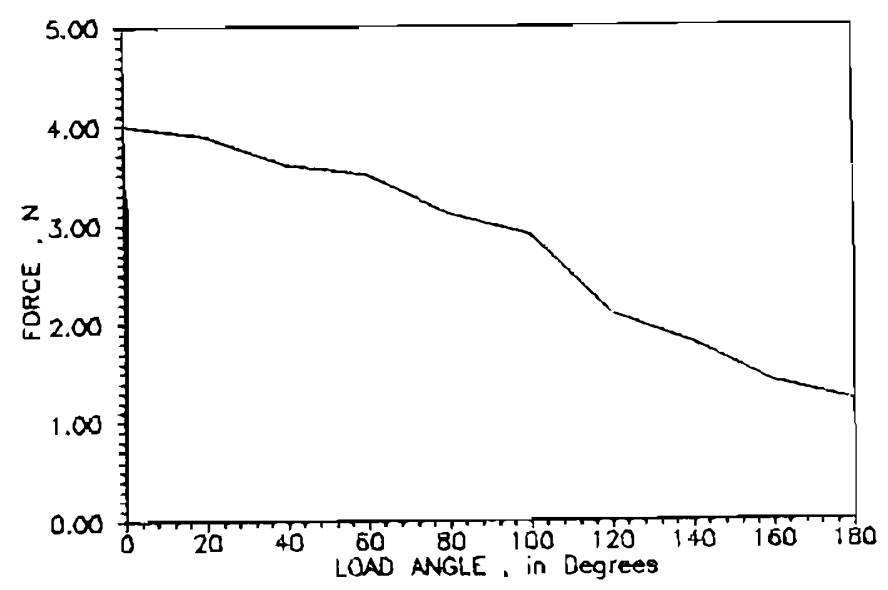

Fig.(4): Normal force versus lood angle.

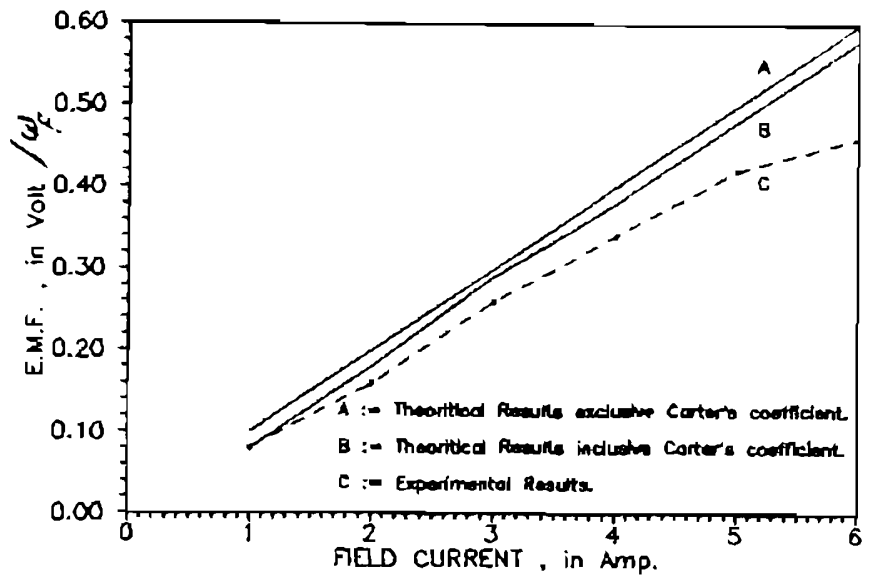

Fig. (5): Induced EMF per Phase per Angular Frequency in Armature Winding Versus Field Current. 